WS5-A03

\title{
3D Lithological and Structural Modeling of the Kevitsa 2D and 3D Reflection Seismic Data - A Case Study
}

\author{
E. Koivisto* (University of Helsinki), A. Malehmir (Uppsala University), T. \\ Voipio (First Quantum Minerals Ltd) \& C. Wijns (First Quantum Minerals \\ Ltd)
}

\section{SUMMARY}

The Kevitsa mafic-ultramafic intrusion in northern Finland hosts a large, disseminated nickel-copper sulphide deposit. We present a 3D lithological and structural model of the Kevitsa area, obtained via modeling of 2D and 3D reflection seismic data from Kevitsa. The Kevitsa 3D model contains modeled surfaces of the contacts between the main lithological units and a model of the magmatic layering within the intrusion. The Kevitsa main mineralization is thought to be controlled by the lateral extents of this discontinuous, smaller-scale magmatic layering within the intrusion. An improved knowledge of the geometry of the intrusion, and in particular of the extent of the internal magmatic layering, provides a framework for near-mine and deep exploration in the area. Better control on the position of the basal contact of the intrusion provides an exploration target for the contact-type mineralization. The original purpose of the 3D seismic survey was to provide a structural framework for geotechnical planning of the mine, and accordingly the 3D seismic data were used to create a structural model of the 3D cube. The modeled structures reveal a complex pattern of fault and fracture zones, some of which will be important for slope stability and operational planning at the mine. 


\section{Introduction}

The Kevitsa mafic intrusion in northern Finland hosts a large, low-grade, disseminated nickel-copper sulphide deposit $(0.27 \% \mathrm{Ni}, 0.40 \% \mathrm{Cu})$, with also significant PGE and gold contents. The proved and probable mineral reserve is 160.6 million tons at a Ni cut-off of $0.1 \%$ (Gregory et al. 2011). Open-pit mining commenced by First Quantum Minerals Ltd in 2012, and the planned final pit depth is about 550 meters. The forecast mine life is more than 20 years.

The Kevitsa intrusion is emplaced within layered sedimentary and volcanic rocks of the Central Lapland Greenstone Belt (Figure 1). The main mineralization occurs within the olivine-pyroxenite part of the intrusion and is thought to be controlled by the extent of laterally discontinuous, smallerscale magmatic layering within the intrusion: with plagioclase-bearing olivine websterite on the top, olivine websterite in the middle, and olivine pyroxenite at the base of each layer (Gregory et al. 2011). The mineralization becomes higher grade at the bases of the layers. Other types of economically interesting mineralization include contact-related and possibly remobilized sulphides that are usually semi-massive to massive, rich in nickel and copper, and occur at or below the basal contact of the intrusion.
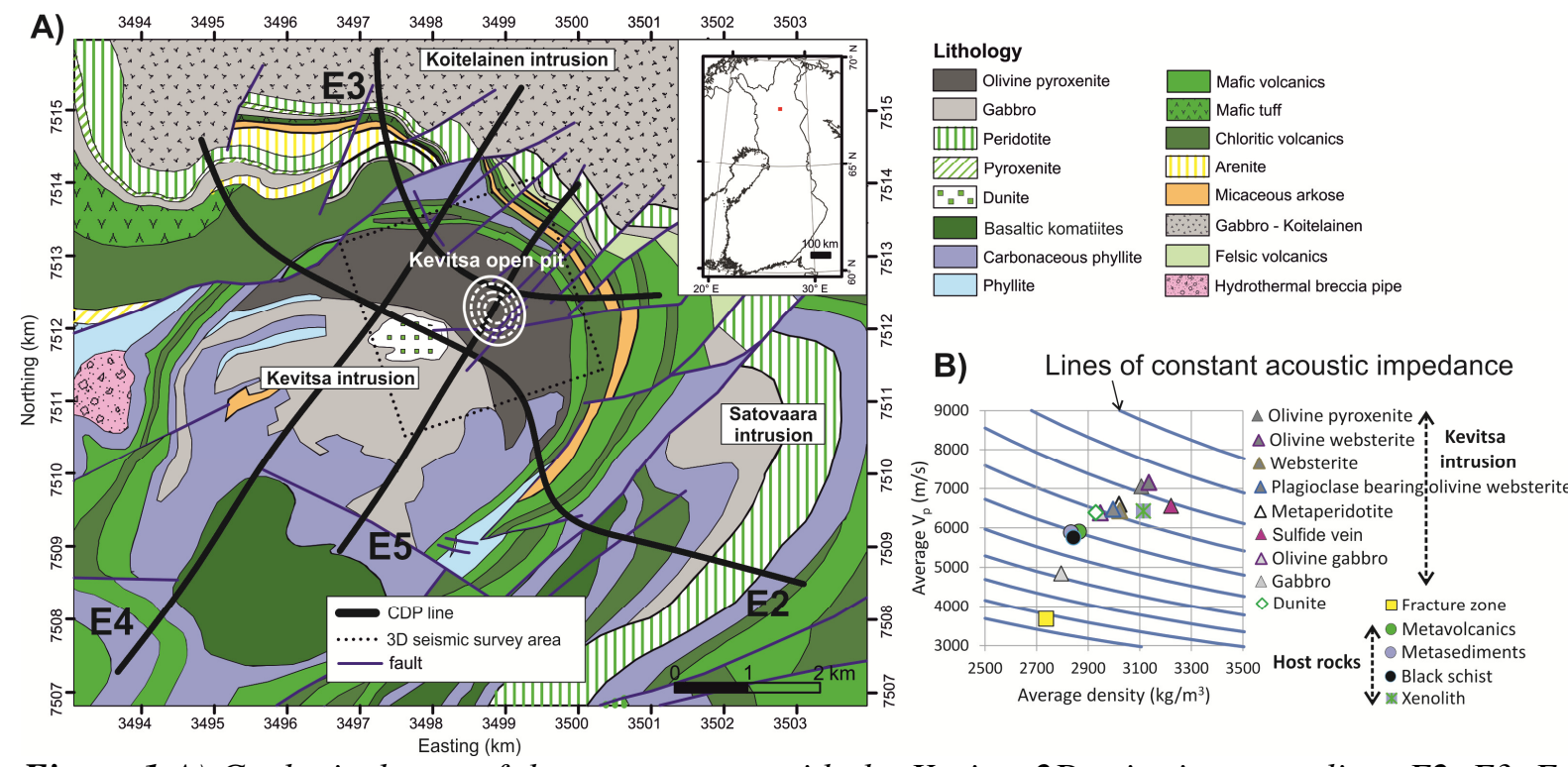

Figure 1 A) Geological map of the survey area, with the Kevitsa 2D seismic survey lines E2, E3, E4 and $E 5$ and the $3 D$ seismic survey area. B) Average P-wave velocity versus density measured in 12 drill holes in the study area. The difference between two sets of blue lines should be enough to cause a seismic signal at the contact between two lithologies. Figures modified from Koivisto et al. (2012).

Since the discovery of the Kevitsa deposit in 1987, the Kevitsa intrusion has been a target of numerous geological and geophysical investigations. Almost 1000 holes have been drilled in the area. However, most of the holes are shallow and only a few are deeper (more than $1 \mathrm{~km}$ ), thus hindering the creation of a comprehensive geological model of the area. Crucial to this work, excellent reflection seismic data have been collected at Kevitsa. First, in December 2007, four inter-connected 2D reflection seismic profiles were acquired (Kukkonen et al. 2009; Koivisto et al. 2012). In 2010, the 2D lines were followed by a VSP and 3D seismic survey for mine planning and deep mineral exploration purposes (Malehmir et al. 2012; 2014; Figure 1A). These seismic data have revealed a detailed architecture of the intrusion and surrounding units. Together with extensive drill hole data, the seismic data were used to create a comprehensive 3D lithological and structural model of the area.

\section{Methods and results}

Interpretation of the seismic data is based on extensive drill hole data available from Kevitsa. From the sonic data, it is evident that the base of the intrusion, and thus the contact-type mineralization 


\section{Amsterdam ' 14}

associated with it, provides an excellent seismic target (Figure 1B). Surprisingly, the seismic data also reveal manifold internal reflectivity within the ore-bearing part of the intrusion (Figure 2A). Sonic data was used to tie the reflectors to the magmatic layering associated with the main mineralization.
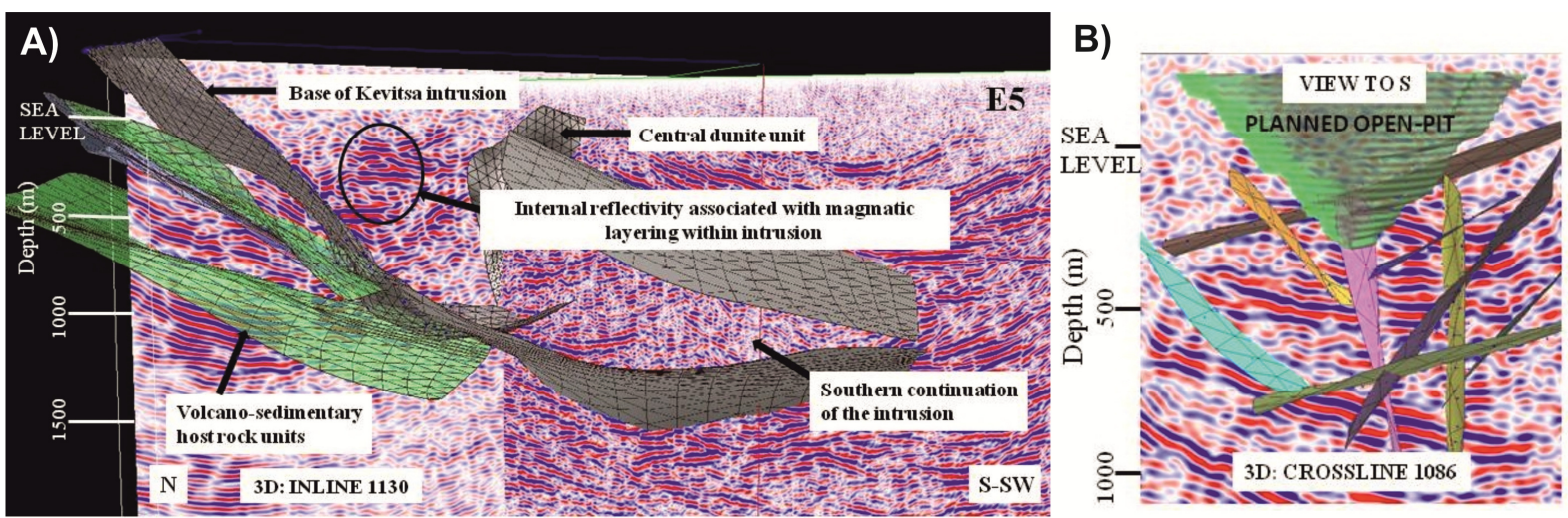

Figure 2 A) An example of the lithological units modelled from the Kevitsa reflection seismic data. B) An example of modeled structures in the close vicinity of the planned open pit.

The Kevitsa 3D model contains modeled surfaces of the contacts between the main lithological units and a model of the magmatic layering within the intrusion (Figure 2A). The original purpose of the 3D seismic survey was to aid with the geotechnical planning of the mine, and the 3D seismic data were also used to create a structural model of the 3D cube (Figure 2B). At Kevitsa, very few structures are reflective, and generally the 3D structural model consists of modeled persistent breaks and offsets in the reflectors, which have been interpreted as prevailing structures.

\section{Conclusions}

The Kevitsa reflection seismic data have greatly improved the understanding of the general architecture of the complex, as well as that of its internal makeup. For example, the modeling has revealed a previously unknown deeper southern extent of the intrusion (Figure 2A). An improved knowledge of the geometry of the intrusion, and in particular of the extent of the discontinuous magmatic layering within the intrusion, provides a framework for near-mine and deep exploration in the area. Better knowledge of the basal contact of the intrusion provides an exploration target for the contact-type mineralization. The modeled structures reveal a complex pattern of fault and fracture zones, some of which will be important for the geotechnical planning of the mine, and for understanding the structural control of the deposits in the area.

\section{References}

Gregory, J., Journet, N., White, G. and Lappalainen, M. [2011] Kevitsa copper nickel project Finland: technical report for the mineral resources and reserves of the kevitsa project. First Qantum Minerals Ltd, $52 \mathrm{p}$.

Koivisto, E., Malehmir, A., Heikkinen, P., Heinonen, S. and Kukkonen, I. [2012] 2D reflection seismic investigations in the Kevitsa Ni-Cu-PGE deposit, northern Finland. Geophysics, 77, WC149-WC162.

Kukkonen, I., Lahti, I., Heikkinen, P. and HIRE Working Group [2009] HIRE Seismic Reflection Survey in the Kevitsa Ni-PGE deposit, North Finland. Geological Survey of Finland, Unpublished report Q 23/2008/59.

Malehmir, A., Juhlin, C., Wijns, C., Urosevic, M., Valasti, P. and Koivisto, E. [2012] 3D reflection seismic investigation for open-pit mine planning and exploration in the Kevitsa Ni-Cu-PGE deposit, Northern Finland. Geophysics, 77, WC95-WC108.

Malehmir, A., Koivisto, E., Manzi, M., Cheraghi, S., Durrheim, R., Bellefleur, G., Wijns, C., Hein, K. and King, N. [2014] A review of reflection seismic investigations in three major metallogenic regions: the Kevitsa Ni-CuPGE district (Finland), Witwatersrand goldfields (South Africa), and the Bathurst Mining Camp (Canada). Ore Geology Reviews, 56, 423-441. 